\title{
REPRESENTAÇÃO EM CONSELHOS DE POĹTICAS PÚBLICAS: O CASO DA EDUCAÇÃO EM SÃO BERNARDO DO CAMPO
}

\section{RESUMO}

Este artigo tem por objetivo discutir os novos processos de representação e participação advindos da abertura democrática proposta na Constituinte de 1988, em especial os Conselhos de Políticas Públicas. Afinal, quais são as contribuições factuais para a democracia, ampliação do debate e empoderamento da sociedade provenientes dos Conselhos? Como objeto particular de estudo, tem-se a gestão atual (2009- 2012) do Conselho Municipal de Educação de São Bernardo do Campo. O artigo parte de uma discussão teórica sobre a democracia representativa e seu caminhar até a gestão participativa e os avanços na atualidade, no caso brasileiro, assim como o escopo da discussão em torno dos conselhos hoje. Segue-se uma contextualização do objeto de estudo, a partir da qual se desdobram os resultados e elucidações. Foi possível observar, dessa maneira, que os conselhos ainda estão em vias de organização, e que precisam se fundar como instituição estável para prestar uma representação adequada, baseada em accountability, ou prestação e contas, e diálogo. Ainda não é comum a prática de trazer ao Conselho as demandas das categorias representadas, e sim os pontos de vista de cada indivíduo eleito. Para tal, quatro frentes de otimização são propostas: a comunicativa, a institucional/gerencial, a estruturante de rede e a regulatória.

PALAVRAS-CHAVE Conselhos de Políticas Públicas, representação, gestão participativa, democracia.

\author{
Tamara Ilinsky Crantschaninov tamaracrants@gmail.com \\ Bacharel em Gestão de Políticas Públicas (EACH/USP) e mestranda em Administração Pública e Governo (EAESP/FGV). \\ Filiação institucional: Escola de Administração de Empresas de São Paulo - Fundação Getulio Vargas.
}

Artigo submetido em 06.09.2010 e aprovado: 11.06.2011

\begin{abstract}
This research has, as objective, to discuss the new process of representation and participation arising from the Brazilian 1988 Constitution's democratic opening, specially Public Policy Councils. After all, what are the contributions, in fact, to democracy, magnifying of the debate and society empowerment proceeding from Councils? As particular object of study, it had the current management (2009-2012) of the City Council of Education of São Bernardo do Campo. The article begins with a theoretical quarrel on the representative democracy and its way until the participatory management and the advances at present time in the Brazilian case, as well as the target of the quarrel around the Councils today. A contextualization of the study object is followed, from which it unfolds the results and briefings. It was possible to observe, in this way, that the Councils still are in its organization ways, and that they still need to establish as steady institution to give an adjusted representation, established in accountability and dialogue. The practice to bring to the Council the demands of the represented categories are not yet the practical, but only the individual points of view of each counselor. For this, four fronts of optimization are considered: the communicative, institutional/managerial, the net structuring and the regulatory one.
\end{abstract}

KEYWORDS Public Policy Councils, representation, participatory management, democracy. 


\section{INTRODUÇÃO: DILEMAS INTERNOS NA CONSTRUÇÃO DA DEMOCRACIA PARTICIPATIVA BRASILEIRA}

A pesquisa em questão visa estudar processos relativos à gestão participativa, tendo como foco os Conselhos de Políticas Públicas. Mais especificamente, busca avaliar quais são as reais limitações dos Conselhos em relação a condicionantes da própria democracia, e, de acordo com essa ponderação, verificar em que grau conseguem se tornar mecanismos legítimos de participação social. Para tal, utiliza-se um estudo de caso focal - o Conselho de Educação Municipal de São Bernardo do Campo, município da grande São Paulo. A legitimação da participação, aparentemente presente por força de lei, é frágil quando se analisam questões como a transparência nas eleições dos conselhos, o próprio perfil dos eleitos (se representam a comunidade de forma igualitária), o processo de deliberação dos conselhos (ou seja, a real proporção entre as decisões tomadas entre conselheiros da população e conselheiros governamentais), a relevância ou própria existência do debate dentro desse aparelho, entre outros aspectos. Dessa maneira, busca-se entender, por meio da análise pontual, qual é a contribuição desse Conselho de Políticas Públicas para uma sociedade mais igualitária quanto ao acesso a mecanismos de poder, tendo em vista o recente processo de ampliação democrática brasileira, o que torna essa questão ainda mais relevante.

Bartholo et al. (2003) acreditam que exista uma crise de legitimidade proveniente da democracia representativa, quando a representação reduz as possibilidades de participação de grupos minoritários. A democracia participativa, exteriorizada, por exemplo, nos Conselhos, tende a sanar essa crise. Contudo, a maneira com que esse processo é feito precisa, de fato, englobar os excluídos, para ser legítimo. Esse estudo também se faz necessário a fim acompanhar a formulação e implementação desses novos centros de poder. A partir do momento em que as eleições não são mais o único instrumento legal de punição ou reconhecimento do governo, já que não permitem um controle em tempo real, mas somente uma avaliação retrospectiva (MANIN, PRZEWORSKI e STOKES, 2006), quando os danos já foram causados, é preciso repensar e reavaliar como estão sendo construídas as novas instâncias de empoderamento.

Apesar de ser uma instituição legalmente empoderada, Gurza Lavalle, Houtzager e Castello (2006a) acreditam que o questionamento da legitimidade desses órgãos é contundente por apresentarem mecanismos diferentes dos tradicionais - basicamente o mecanismo eleitoral por si só. Como seu processo acontece de forma distinta, mediante uma reconfiguração da representação, é preciso pensar como ela é organizada a fim de não representar uma ameaça para a linha de pensamento que lhe deu origem. Esses perigos podem advir tanto das consequências da falta de mecanismos de accountability, ou prestação de contas, entre os conselheiros e os grupos representados (GURZA LAVALLE, HOUTZAGER e CASTELLO, 2006a) quanto da própria inexistência de diálogo entre representantes e representados, para compatibilizar as demandas efetivas com as discutidas em âmbito do Conselho. Como foram as organizações da sociedade civil que repensaram e formataram os novos modelos democráticos da atualidade no Brasil, tende-se a imaginar a atuação desses órgãos como imperativamente democrática e representativa (LÜCHMANN, 2007), situação ainda mais clara no caso dos Conselhos de Políticas Públicas, onde a imediata relação

[...] entre organizações da sociedade civil e defesa de direitos dos setores excluídos vem tornando quase que automático o vínculo entre sociedade civil, participação e representação, o que requer uma maior 
problematização acerca do grau de legitimidade da representação destes atores no interior destes espaços. (LÜCHMANN, 2007: 149).

Assim, é preciso quebrar o pressuposto de que existe uma compatibilidade total entre sociedade e sociedade civil organizada, dado que o fato de a representação acontecer no estrato social não é garantia para uma dinâmica real de representação. Mesmo nessas esferas, existe espaço para a proliferação de clientelismos e patrimonialismos, ainda que de forma inercial e fruto da fragilidade da instituição, e não necessariamente da má vontade dos representantes. Gurza Lavalle, Houtzager e Castello (2006a) deixam claro que os atores da sociedade civil obedecem a lógicas que não necessariamente são compatíveis com a ampliação democrática. (GURZA LAVALLE, HOUTZAGER e CASTELLO, 2006a).

O estudo desses instrumentos de poder que são dados, legalmente, nas mãos da sociedade civil é ainda de grande importância em um país onde, tradicionalmente, a política é feita de cima para baixo, com planos implantados de forma centralizada. A reversão desses papéis, se é que de fato acontece, representa uma mudança estrutural que busca compensar séculos de disparidades na forma de condução do Estado brasileiro. Existe uma redefinição de atribuições entre sociedade e governo, marcada pela participação e descentralização (BARTHOLO et al., 2003). Além de ser uma nova tendência, configura-se como uma nova alternativa de democratização popular. Contudo, até que ponto é democrática, e até que nível é popular? Os Conselhos permitem a transparência entre sociedade e governo, ou continuam como espelho das velhas gramáticas brasileiras?

O trabalho é estruturado em três grandes fases: a primeira retoma, por meio de revisão bibliográfica, os conceitos das teorias democráticas e seus principais autores, bem como as relações entre a democracia representativa e a participativa. Nessa ocasião também é realizado um levantamento do que se tem estudado atualmente sobre gestão participativa e, mais propriamente, conselhos. Num segundo momento, é feita a contextualização do objeto de estudo, levando em conta o surgimento dos Conselhos no Brasil, a conjuntura da política local e as bases legais dos Conselhos em questão. Em seguida, é feita uma explanação do desenvolvimento da pesquisa, para a qual foram utilizadas entrevistas em profundidade e pesquisas quantitativas com os conselheiros, seguida de seus resultados e conclusões.

\section{O PROBLEMA DA DEMOCRACIA REPRESENTATIVA E A EMERGÊNCIA DOS CONSELHOS DE POLÍTICAS PÚBLICAS}

A proposta de uma sociedade que resolve suas demandas por meio de Conselhos setoriais surge como resposta à teoria hegemônica da democracia, ligada à corrente liberal. Dessa forma, os Conselhos são um modelo de aplicação prática da teoria anti-hegemônica da democracia, a qual contém a elucidação da democracia participativa e da democracia deliberativa. A transição democrática pode ser lida como a crise de dupla patologia (BOAVENTURA SANTOS, 2002): a da participação em si, tendo em vista os altos índices de abstencionismo, e a da representação, já que os cidadãos se veem cada vez menos representados. Essa crise deu força ao movimento de busca de mecanismos alternativos, que pudessem representar de forma mais clara os interesses dos cidadãos frente ao Estado. Passou-se a dar um valor maior à importância da mobilização coletiva na construção de uma democracia palpável, e as eleições deixam de esgotar todas as formas de influência pública no governo. Mas, afinal, é possí- 
vel que o povo governe diretamente? Se for possível, com que qualidade e exequibilidade? São questões como essas que a democracia participativa busca responder. Essas práticas nascem da discussão sobre os papéis dos atores da sociedade e uma possível reconfiguração desses papéis.

$\mathrm{Na}$ corrente hegemônica, estão os defensores da democracia representativa, que acreditam na importância da liberdade como fator essencial na busca de representação igualitária dos interesses que compõem a sociedade a ser governada. Assim, o sucesso da democracia é a garantia de que todos podem aceder ao governo por meio das eleições, mediante as quais os representantes estão autorizados a agir em nome da soberania popular, enquanto a sociedade civil está livre para buscar sua satisfação por caminhos individuais. Contudo, Michels (1982) acredita que a multidão acaba por anular os indivíduos, numa contribuição ao individualismo próprio da democracia proposta por Tocqueville (1835). Segundo ele, o povo perde sua soberania ao votar, em vez do contrário, porque aceita ser representado, em vez de pessoalmente defender seus interesses. A heterogeneidade das vontades individuais não pode ser resumida num único representante. Seu único direito passa a ser o de eleger novos senhores de tempos em tempos. Citando Mosca (1968), a partir do momento em que termina o momento eleitoral, o eleito perde contato com o povo e passa a governar segundo seus próprios interesses. Em suma, a única arma que o cidadão tem é o voto. Por meio dele, o indivíduo tem que avaliar políticas, governantes, e decidir quem continua com o poder. Mas existem momentos em que não é possível eleger os melhores políticos e as melhores políticas. O voto também é custoso, porque se informar sobre os melhores políticos e políticas custa algo, seja tempo ou dinheiro. O controle dos eleitores se quebra quando eles nunca têm informações suficientes para saber se votaram na pessoa certa, e estão sempre pensando que o concorrente era melhor. Sabendo que, na próxima eleição, o concorrente será eleito, o atual governante escolhe extrair rendas privadas de sua posição pública, deixando de lado os desejos da população (DAHL, 1997).

Para que se aumente o nível de representação, Manin, Przeworski e Stokes (2006) sugerem que os eleitores devem ter capacidade para responsabilizar o governo por suas ações, assim como devem ter poder para tirar do governo políticos ruins. Esse poder, contudo, deve estar institucionalizado além do voto - e é preciso mais do que isso para que as políticas sejam realmente avaliadas, para que o governo seja monitorado, e, além disso, é preciso mais do que eleições para que as demandas reais da população não se percam em meio ao emaranhado da vida pública. A democracia liberal, representada pela liberdade de escolher seus representantes, mas sem a garantia de efetiva representatividade, deixa obscuros os grupos minoritários que não têm força suficiente para se eleger.

A partir dessa falha da teoria representativa, surgem modelos que buscam suavizar a disparidade entre a sociedade civil e seus representantes, a fim de que a sociedade se autorrepresente. Nesse sentido, surgem as teorias da democracia participativa, que partem do pressuposto de que um governo verdadeiramente democrático é aquele organizado por instituições construídas num processo coletivo de discussão e deliberação pública entre todos os cidadãos (LÜCHMANN, 2007). Apesar de as pretensões da teoria participativa serem altas, ela não entra em conflito com a definição democrática de escolha dos líderes pela população, principalmente em se tratando de áreas extensas, já que a influência de um só indivíduo é mínima. O desafio então é dar incentivo suficiente para que a população participe e se interesse pelos assuntos públicos, quando sabe que não é capaz de mudar isoladamente a situação em que vive. 
Avritzer e Navarro (2003) analisam a concretização dessa oportunidade por meio de certos princípios gerais que marcam as novas relações de poder nos círculos de debate: a participação é aberta a todos os cidadãos, sem distinção de status ou conhecimento específico; a combinação da democracia representativa e direta; e a alocação de recursos por meio do consenso dos especialistas com a população, ideia predominante nos Conselhos. Esses princípios desdobram-se de diversas formas, moldando-se às características regionais, para formar conselhos, orçamentos participativos, observatórios, entre outros. A redefinição das formas de fazer política proposta por Boaventura Santos (2002) é dada, segundo Avritzer (2003), pela emergência das organizações sociais no contexto pós-ditadura brasileiro, além da maneira específica de se relacionar com o Estado como cooperador, complementador ou opositor. O fenômeno do associativismo é responsável, então, pelo surgimento da discussão sobre o papel da organização da sociedade no Estado, principalmente a partir do movimento de construção popular da Constituição de 1988, por meio das emendas populares. Dagnino (2004) acredita que transformar a sociedade civil até então apagada em um organismo vibrante e responsável pelo sucesso de políticas públicas por meio de seu ativismo político é uma tarefa mais complicada do que o disposto na Constituição de 88. Apesar da disposição governamental em aderir a essas práticas, a jovialidade das experiências de participação democrática, às quais são atribuídas grandes responsabilidades, não é capaz de desempenhar com clareza o seu papel, o que resulta numa perversidade da abertura democrática.

A partir da contribuição desses autores no traço das vias da democracia participativa, é possível discutir com maior especificidade a questão dos Conselhos de Políticas Públicas no Brasil. Os Conselhos vieram para suprir a carência de instituições de diálogo entre o governo e a sociedade após a abertura democrática. São instrumentos empoderados para repassar demandas aos responsáveis e negociar condições diretamente e sem interrupções, receber informações do governo e continuar com essa dinâmica de forma contínua. Por quebrarem o antigo paradigma brasileiro do distanciamento entre as duas esferas, seu funcionamento pode, muitas vezes, ter falhas pela resistência dos tradicionais donos do poder - os políticos eleitos, a burocracia, os legisladores. Os Conselhos participativos no Brasil existem para complementar a ação da democracia representativa, aumentando a sensibilidade dos governantes às reais necessidades da sociedade. Essa coexistência se reflete na paridade entre membros da sociedade e membros do governo na composição de sua estrutura, para garantir um dialogo entre as duas forças legítimas. Avritzer (2007) mostra que existem, atualmente, cerca de 28 mil Conselhos de Políticas Públicas no Brasil (IBGE, 2001). São Conselhos Setoriais provenientes do debate constituinte de 88, e que se tornaram ferramentas para a área de saúde, assistência social, educação, turismo, cultura, meio ambiente, entre outras. Os Conselhos são constituídos de representantes da sociedade civil e do governo. Segundo o autor, "o papel dos participantes no Conselho é deliberar, juntamente com o poder público, [...], exercer controle direto e regular as ações do governo" (AVRITZER, 2007). Os Conselhos, por sua legalidade e extensa rede de cobertura, tornaram-se um dos principais instrumentos de transmissão de demandas para o governo, diretamente pela sociedade. É uma tentativa de reversão de prioridades por meio do poder de deliberar entregue à população. Apesar desse avanço democrático, Avritzer (2007) explana que não se pode considerar de olhos vendados a relação entre a institucionalização dos Conselhos e uma melhora efetiva nas condições de vida da população. Ainda existem discussões sobre a pressão real que os Conselhos são capazes de exercer na definição da 
agenda, e se os Conselhos realmente promovem o acesso geral da sociedade à discussão deliberativa. Além disso, não existe uma relação demarcada entre participação e redução da pobreza, sendo o primeiro capaz de modificar o segundo.

A relação entre Conselhos e democracia participativa é explicitada por Tatagiba (2005). Segundo ela, a alocação dos recursos de forma eficiente depende da participação da sociedade como um ator deliberativo dessa questão. Os conselheiros da sociedade civil apresentam dificuldades em compactar os interesses de uma sociedade plural em um espaço aberto, mas restrito, além de lutarem contra a resistência do Estado em abrir mão de poder de deliberação. De fato, são as atores governamentais que ditam os interesses temáticos, mantendo a centralidade no Estado e mantendo os conselheiros da sociedade civil como consultivos, como uma maneira de legitimar suas próprias proposições. A autora ressalta que praticamente não existe debate entre os dois setores do Conselho, e que as decisões são tomadas por consenso. Tatagiba (2005) acredita que, apesar de os conselhos representarem um grande avanço para a abertura à participação da sociedade, hoje seu poder está mais centrado no controle social do que na proposição de políticas.

\section{PERCEPÇÕES DE REPRESENTAÇÃO E ABERTURA HISTÓRICA PARA PARTICIPAÇÃO NO BRASIL}

Segundo Ferreira (1993), a evidente fragilidade por meio da qual se desenvolve a cultura política no Brasil é resultado direto do processo de colonização implementado pela metrópole, assim como da formação de um governo elitista, destacado da sociedade comum. Faoro (1925) descreve a influência da formação da burocracia brasileira, reflexo da portuguesa, como principal razão do estabelecimento de um sistema patrimonialis- ta no Estado brasileiro, onde os cargos públicos não são exercidos em nome do bem-estar social, mas na expectativa de benefícios privados. A partir desse ideário, que, já de início, frustra a construção de uma sociedade democrática e cidadã, o representante se torna o líder que é herói, e não o que faz parte do coletivo (FERREIRA, 1993). Não se busca representação, e sim proteção de alguém maior, mais forte, capaz de defender a sociedade por ser mais, e não por ser igual. Esse paradigma fica claro na formação do governo Vargas (19301945), um Estado populista, baseado na ideia do governo protetor, "pai dos pobres". A dependência dá espaço para o ressentimento, que bloqueia uma ação de resposta, por ser gêmea do sentimento de impotência (FERREIRA, 1993). Essa impotência em se ver como agente formador do Estado transforma a sociedade em cúmplice dos caminhos não institucionais para a resolução de seus problemas.

Lamounier (2005) coloca que "o alvo por excelência da descrença nacional sempre foram os mecanismos de representação política: eleições, partidos e legislativo". Carvalho (2004) completa que a relação do povo com o governo é de "distância, suspeita, quando não de aberto antagonismo". Ainda segundo Ferreira (1993), a ineficiência de nossa democracia representativa se ampara justamente na personalização de acesso, onde uns tem mais potencialidade de acesso ao Estado do que outros. A construção de uma democracia participativa, nesse cenário, precisa ser pensada para desvirtuar esse paradigma, e não ser conformada como uma extensão deste. É necessário quebrar a lógica do quem me governa, me governa por não ser igual a mim, por ser substância central da gestão participativa a autoadministração. Lamounier (2005) considera que, a partir da Constituinte de 88 , pode-se falar de uma "decolagem democrática", já que o jogo eleitoral é regularizado, com a incerteza sobre o resultado final e a pacificação dos enfrentamentos (LAMOUNIER, 2005). Por 
meio da CF/88, o brasileiro reconquistou, além do direito de eleger e ser eleito, a possibilidade de influenciar diretamente o governo, como discorre o artigo 14:

Art. 14. A soberania popular será exercida pelo sufrágio universal e pelo voto direto e secreto, com valor igual para todos, e, nos termos da lei, mediante: [...]

III - iniciativa popular.

Esse processo foi ainda impulsionado por uma indução externa, que, por meio das agências internacionais (como o Banco Mundial e Fundo Monetário Internacional), colocava no centro da reforma política a descentralização do poder e a busca de uma gestão mais eficiente (LEITE, PERES e IGLECIAS, 2009). Esse fenômeno foi embarcado na reforma gerencial brasileira de 1995, proposta por Bresser-Pereira (BRESSER-PEREIRA, 2008). O novo modelo se propunha a responder uma problemática referente ao tamanho do Estado, que passava por uma crise de legitimidade como provedor único de serviços essenciais.

Em conjunto a essa pressão externa, as organizações da sociedade civil, que se apresentavam contrárias à ação do governo tradicionalmente devido à ditadura, passaram a dialogar com este, numa nova instância democrática. Esse novo contexto deu origem à multiplicação de organizações da sociedade que passaram a atuar no governo. O Conselho foi o modelo administrativo encontrado para garantir essa inclusão no governo e tornar prática a participação prevista constitucionalmente.

Bartholo et al. (2003) descrevem:

Em geral, cabe aos conselhos gestores nacionais de políticas sociais definir as políticas públicas nacionais, atuando na formulação e elaboração de diretrizes gerais e na definição dos programas federais prioritários. A partir desta orientação geral, cabe aos conselhos estaduais e municipais, juntamente com as secretarias executivas estaduais e municipais, programar, aperfeiçoar e executar os serviços sociais localmente, além de controlar e fiscalizar o uso e aplicação de recursos que são transferidos dos Fundos Nacionais para os Fundos Estaduais e Municipais. (BARTHOLO et al., 2003: 07).

Os conselhos se caracterizam, então, como órgãos públicos colegiados, diretamente subordinados ao Poder Executivo, e vinculados à Secretaria que lhes diz respeito. A composição do Conselho obedece à lógica de tanto trazer ao debate os representantes de setores excluídos quanto os próprios excluídos (LÜCHMANN, 2007). Assim, sua legitimidade está consolidada na suposição de que esses representantes e participantes são a essência e o foco das questões tratadas no âmbito conselhista.

\section{OBJETO DO ESTUDO E DESENVOLVIMENTO DA PESQUISA: O CONSELHO LEGAL E 0 CONSELHO REAL}

O Conselho Municipal de Educação de São Bernardo do Campo foi criado em 1976 pela Lei Municipal $n^{\circ} 2.240$, que consolida a reforma administrativa do município. A escolha do objeto de estudo específico foi dada devido à longa atividade do Conselho em questão, já que sua lei de criação data de 1976, e a maior facilidade e acessibilidade às documentações e reuniões do Conselho, permitindo um estudo de caso mais aprofundado. O órgão, desde o início, foi criado com funções consultivas, normativas e deliberativas, e as mantém até a atualidade. As atribuições citadas na lei ainda garantem uma função fiscalizadora. Assim, o CMED foi escolhido por seu amplo leque de funções e solidez histórica, permitindo a investigação de diversos pontos de 
escopo democrático.

$\mathrm{O}$ artigo $2^{\circ}$ da lei de criação do Conselho diz que

Art. $2^{\circ}$ A ação administrativa, sempre a serviço do bem comum e dentro do quadro prescrito pela legislação federal, estadual e municipal, obedecerá, permanentemente, aos seguintes princípios fundamentais:

I - planejamento;

II - coordenação;

III - descentralização;

IV - delegação de competência;

$\mathrm{V}$ - controle.

Assim, o Conselho de Educação surge em um momento de renovação da administração pública da cidade, que visa criar um sistema de coordenação de políticas, fazendo com que elas sejam planejadas de forma a garantir a sua eficiência. É interessante ressaltar que o Conselho surge, ainda, em momento ditatorial, não sendo criado com funções de abertura ao diálogo e à democracia, obviamente, mas inserido na lógica de reforma do Estado descrita acima.

A Lei Orgânica do Município (datada de 1990) define que:

Art. 181. O Conselho Municipal de Educação é o órgão normativo, consultivo e deliberativo do sistema de ensino no Município, com as suas atribuições, organização e composição definidas em lei.

Parágrafo único. Fica assegurada a participação no conselho de que trata este artigo de especialistas em educação, professores, pais e alunos, indicados pela respectiva associação.

Por meio da análise das competências do Conselho (Lei $n^{\circ}$ 5.189/2003), percebe-se uma tendência muito mais consultiva do que deliberativa do Conselho, mediante a repetição de verbos como "propor", "opinar" e "assistir". Ou seja, o Conselho tende a ser um assessor dos conselhei- ros governamentais dentro do Conselho.

Foi escolhida a gestão de 2009-2012 para ser estudada por estar situada num ponto de inflexão no governo da cidade, que passa por uma transição de um governo tradicionalmente insulado para uma administração que tem como discurso a exaltação da participação popular. Esse período também foi escolhido pela possibilidade de acompanhamento das reuniões, o que possibilita uma análise mais abrangente da realidade, além do discurso dos conselheiros, previsto por meio das entrevistas.

Dos 14 conselheiros atualmente empossados (duas das vagas previstas em regimento estão em vacância), foram entrevistados 12 representantes $(85,7 \%)$. Considerando que dois conselheiros se abstiveram, 10 entrevistas foram utilizadas na composição desta análise $(71,4 \%)$. Segundo a presidente do Conselho, as duas vagas em vacância, pertencentes à representação da sociedade, não encontram quem as queria preencher, num esvaziamento claro do significado do Conselho para a sociedade civil - neste momento, pode-se hipotetizar que os custos da participação ultrapassam os ganhos. Considerando que sete vagas são destinadas ao poder Executivo, o Conselho funciona hoje paritariamente, ou seja, com o mesmo número de conselheiros do lado governamental e da sociedade. Para efeitos de comparação, dos 630 Conselhos de Educação do estado de São Paulo, 550 são paritários (IBGE, 2010). $O$ perfil dos conselheiros condiz com a situação debatida, ou seja, são em geral pessoas que já passaram pelo seu próprio processo de educação e agora discutem a educação de alunos e filhos, sendo a classe naturalmente tendenciosa a participar das discussões sobre o sistema de ensino municipal - em sua maioria mulheres na faixa dos 35-50 anos. Quanto aos grupos representados, 20\% dos participantes são provenientes do Poder Executivo municipal e $20 \%$ da Secretaria de Educação, resultando em $40 \%$ da composição 
governamental. Professores das escolas de educação básica, pais de alunos das escolas da rede pública de ensino fundamental, representantes da rede estadual de ensino e representantes do ensino superior somam, cada categoria, $10 \%$ da representação ( $10 \%$ se abstiveram). São funcionários públicos 70\% dos conselheiros em questão, outros $20 \%$ são empregados na iniciativa privada e 10\% se abstiveram. Em relação à composição por grupos, a presença do governo ainda é maciça e, apesar de não ser mais da metade da composição total, é mais sólida do que os outros grupos, que precisam se aliar para defender suas demandas frente ao órgão. $O$ representante dos professores coloca que "o número de membros indicados pela administração ainda é superior aos outros, o que dificulta as votações, que deveriam ser imparciais". Nas reuniões, essa falta de convergência entre as partes é evidente. Prevalece o embate entre sociedade e governo, resultando em reuniões cansativas, longas e improdutivas. O representante dos pais acredita que "precisam ser criados meios de comunicação e confiança entre as partes". Essa fala pode ser encarada como um resquício do autoritarismo estatal com o qual todos os brasileiros conviveram até o final dos anos 1980. O Estado ainda é visto como avesso à sociedade, e dentro do microespaço de debate do Conselho esse aspecto se evidencia na falta de concordância.

Em relação ao Conselho de Educação em si e seu relacionamento com a classe representada, $70 \%$ dos conselheiros indicaram que se reúnem com os respectivos grupos, sendo que, desses, $50 \%$ declararam que as reuniões ocorrem uma vez ao mês ( $10 \%$ indicaram que as reuniões acontecem conforme a necessidade, e 40\% se abstiveram de responder qual era a frequência das reuniões). Ao serem questionados sobre a prestação de contas, 50\% responderam que existe algum meio de accountabilty do que ocorre no âmbito do Conselho, seja por meio de reuniões (30\%) ou de relatórios (20\%) - sendo que os outros 50\% indicaram não haver prestação de contas entre representantes e representados (são estes representantes da Secretaria Municipal de Educação, do Executivo Municipal, pais dos alunos das escolas de educação básica e das instituições de ensino superior).

Das funções previstas em lei para o Conselho, 50\% consideram que o órgão, atualmente, só responde por funções consultivas. Uns 20\% consideram o Conselho consultivo e deliberativo, e somam 10\% cada uma as opções "somente deliberativo", "normativo e consultivo" e todas as opções. Avaliando, num aspecto geral, a atuação do Conselho, $100 \%$ a consideram positiva, sendo que $80 \%$ apresentaram ressalvas a esse resultado. A maioria (70\%) também considera o Conselho de Educação representativo de sua população, $20 \%$ o consideram em parte representativo e $10 \%$ não o consideram representativo. A ainda latente necessidade de avanço nas questões de eficiência pode ser lida mediante os resultados de avaliação do Conselho. É inevitável concordar que a presença do Conselho, por si só, já é uma conquista não só para os que ali estão, mas para toda a sociedade envolvida no processo educativo. Contudo, os próprios conselheiros (governamentais e da sociedade) reconhecem os problemas que enfrentam, como cita um dos representantes da Secretaria de Educação: "Na medida do possível as ações estão direcionadas para o que é de atribuição. Estamos nos constituindo". Assim, é observável que o processo de democratização do espaço do Conselho ainda não acabou, e que passa não só pela questão de representação, mas também da forma de gerenciamento interno dos debates. Mais importante é a constatação que os conselheiros têm consciência de que estão em momento de aprendizagem. Nesse ponto, é importante ressaltar que a composição do Conselho foi completamente renovada há dois anos, na ocasião de mudança de governo, sendo reeleita somente uma repre- 
sentante, como suplente do representante das entidades de nível superior. Dessa forma, apesar de a criação do Conselho datar de 1976, as renovações constantes de composição, desta última vez de forma praticamente total, o impede de criar uma cultura da instituição, que seja preservada e influencie a gestão interna das ações conselhistas. A própria presidente do Conselho considera que ele está começando seu trabalho agora, depois de se adaptar às mudanças de governo advindas da eleição.

Nesse sentido, a colocação de demandas é, ain$\mathrm{da}$, muito governamental, devido às necessidades que a Secretaria enfrentou de reestruturação e que precisariam passar pelo Conselho. Assim, só agora, com a estabilização dos planos de governo, será possível pautar a agenda pelas demandas dos representantes da população e garantir, numa primeira instância, uma representação dos interesses que chegam via sociedade civil. Assim, o Conselho se torna um receptor de informações das atividades estatais já em curso, e não um produtor de políticas públicas. Fica palpável que sua função é consultiva. Apesar de sua natureza deliberativa - ou seja, tem poder de veto em ações da Secretaria -, os assuntos chegam ao Conselho formatados, previamente deliberados, como mostra a fala do representante dos pais: "Em parte, esta política é muito recente e complicada. Os gestores não abrem muito espaço para discutir projetos e planos. Somos mais aprovadores das ideias e projetos". A representante dos professores de educação básica considera que o órgão "necessita avançar no âmbito deliberativo, pois por força do hábito trabalhamos mais com o âmbito consultivo", e a representante da sociedade civil crê que os conselheiros "precisam ser mais atuantes na formulação de políticas públicas".

Em relação à representação, 90\% se consideram representantes das classes que representam e 10\% não se consideram. Quando questionados sobre o motivo de sua participação no conselho, metade (50\%) considerou como único motivo ter sido indicada pela categoria. Esse dado é indicativo de que a cultura cívica de trazer novas demandas e opiniões da sociedade para o Conselho ainda não está disseminada no município. Escolheram duas opções, a de terem sido indicados e acreditarem na necessidade de discutir políticas públicas de educação, $20 \%$ dos entrevistados. Entre os motivos que justificam por que se consideram representantes, o principal motivo apontado nos comentários foi a participação nas reuniões e discussões. Em relação aos motivos que consideram a representação, a questão propunha diagnosticar a representação presuntiva (GURZA LAVALLE, HOUTZAGER e CASTELLO, 2006b), ou seja, a legitimidade da representação é aferida pelos argumentos defendidos pelos conselheiros. A maior parte dos argumentos se concentrou na essencial presença no Conselho. A representante das entidades de ensino superior considerou sucintamente que "se faço parte, represento em algum grau esse grupo", opinião compartilhada pelos representantes da Secretaria de Educação: "[represento] por acompanhar as reuniões que são organizadas" e "me envolvo com as discussões, procuro buscar informações e propor alternativas para a melhoraria do trabalho realizado em relação à Educação". Assim, a representação não está ligada ao relacionamento com os que são representados, e sim com o processo eleitoral de autorização de representação e seu subsequente exercício. Apesar de 50\% dos entrevistados garantirem a prestação de contas a seus pares, é difícil que esta seja feita no nível municipal, principalmente em classes como a sociedade civil e os pais de alunos, em um município onde convivem mais de 811 mil habitantes e estão em atividade, somente no nível fundamental, 69 escolas. Ao mesmo tempo, a representante da sociedade civil acredita que "precisam ser mais disseminadas as informações e a participação". O acesso à informação é fator fundamental para o exercício 
da cidadania. Sem ela, não se tem subsídio para a cobrança e para a participação. Hoje, a publicação das resoluções do Conselho, assim como das atas de reuniões, ocorre mediante o informativo da Prefeitura, disponível em seu site, porém pouco conhecido. No site da Secretaria de Educação existe um link para a página do Conselho Municipal, ${ }^{1}$ que, apesar de descrever a natureza do órgão e suas atribuições, não dá nenhuma indicação de como contatar o Conselho, do processo eleitoral e das reuniões. Tendo esses pontos em vista, é questionável se a informação é passada, de fato, para os envolvidos no processo de educação, sejam funcionários, sejam pais ou a sociedade civil. As reuniões do Conselho, apesar de acontecerem em espaço supostamente neutro - não na Secretaria de Educação, mas no Centro de Formação dos Profissionais da Educação, local utilizado para congressos, conferências e reuniões gerais do município -, ocorrem em dias da semana e durante a tarde, começando às 14 horas. Ou seja, o Conselho é realmente acessível? Ele realmente pertence à sua população ou está restrito aos eleitos? Levando em consideração esses fatos, supõe-se que a cultura conselhista não está disseminada na população do município, que não tem meios de se apropriar dele por limitações de horário, espaço e acesso à informação.

Sobre o modo como são identificadas as demandas apresentadas no Conselho, a opção mais escolhida (30\%) foi observar a situação da Educação e pensar no que é preciso melhorar. Após discutir sobre as atribuições legais e as realmente exercidas, debate diretamente relacionado ao empoderamento dado à sociedade, entra em pauta a questão da representação. Mais uma vez, os conselheiros, apesar de se considerarem representantes da população municipal, creem que esse processo ainda precisa ser desenvolvido e mais bem representado, inclusive por meio da reforma do Regimento Interno. O Poder Executivo reconhece que "não dialoga com as necessidades dos representados, pois ainda não há mecanismos para tal". Nesse sentido, a presidente do Conselho considera que as categorias representadas não são capazes de abarcar todas as necessidades educacionais da cidade, por serem limitadas ou por demais generalizadas. No caso dos diretores de escola, por exemplo, permitir somente um representante para todas as fases educacionais é exigir muito da capacidade de representação e captação de demandas dessa categoria. Uma das soluções propostas é contar com um representante para cada etapa educacional - creches, educação infantil, ensino fundamental e ensino médio. Contudo, essa limitação transpõe o campo das relações pessoais, tratando-se basicamente de uma barreira institucional, contemplada em regimento, confirmado pelo representante dos pais: "Com ressalvas, o Regimento Interno ainda não dá espaços para a representatividade real". Assim, a reforma em curso do Regimento Interno deve incluir, impreterivelmente, a questão dos setores representados e a composição do órgão.

Tendo em vista os dados apresentados e o acompanhamento do órgão, vê-se claramente que ele ainda procura o caminho (e caminha) para uma situação estável, não configurada neste momento.

\section{DIAGNÓSTICOS: 0 CONSELHO REAL E $O$ CONSELHO QUE QUEREMOS}

O primeiro questionamento teórico que pode ser colocado, a partir da situação retratada, é a capacidade do conselho de responder à problemática da democracia representativa, sendo uma alternativa própria da gestão participativa. Se considerarmos o modelo deliberativo de minipúblico sugerido por Fung (2004), a invenção dos Conselhos deveria pressupor que mais pessoas estão envolvidas no debate pela educação, e que os mediadores eleitos - os conselheiros - são um elo 
entre a comunidade e o governo. De fato, pode-se considerar que existem mais pessoas inseridas na discussão setorial, com poder legitimo de deliberação: exatas nove pessoas, considerando o número total de conselheiros menos o número de conselheiros governamentais - como dois cargos dos conselheiros da sociedade estão em vacância, este número cai para sete. O governo consegue, por meio do que é retratado por esses sete conselheiros, ter uma ideia das demandas e pontos de vista das categorias representadas, mas não se pode considerar que, de fato, exista a construção de um espaço apropriado pela sociedade. Assim, os conselheiros são uma amostragem da população que, por sua condição de similaridade com os demais, é capaz de passar ao Poder Executivo os anseios da população. Ou seja, a representação não é baseada na deliberação conjunta ou na prestação de contas às categorias envolvidas, e sim no conceito de substituição dos que não podem estar presentes, na pessoa do representante (YOUNG, 2006). No momento em que termina a eleição dos conselheiros, "os cidadãos não são mais necessários" (YOUNG, 2006:145), procedimento típico do pensamento democrático-liberal. Rocha (2003) explicita que essa condição é típica dos Conselhos Municipais de Educação, ainda mais pela falta de legislação que imponha o diálogo entre representantes e representados. É importante lembrar, nesse momento, que muitos dos conselhos brasileiros podem funcionar somente na lei como uma forma de legitimação do poder vigente perante a população, mas sem de fato ampliar/ abrir o diálogo e o acesso ao poder. Não se cria uma cultura de participação influenciada somente por esse fator, mas por outros, como os elencados por Abers e Keck (2007) - a frágil ligação entre representantes e representados é um deles, não só entre os conselheiros da sociedade, mas também os governamentais, que encontram pouco respaldo de suas ações em seus companheiros.

A segunda crítica de Abers e Keck (2007) diz respeito à composição do Conselho como naturalmente elitista, sem representar de fato sua população por características inatas. $\mathrm{O}$ regimento interno do Conselho propõe, sobre a sua composição, que seja formada de especialistas em educação e pessoas com experiências distintas. Para exercer os cargos no órgão, pelas características do que é enunciado, a maioria precisa (com exceção dos conselheiros da sociedade civil, a quem é pedida experiência na área, e do representante dos pais de alunos) ter, no mínimo, ensino médio. Essa prerrogativa corresponde à realidade de São Bernardo? Em 2000, somente 24\% da população se encaixava nesse padrão, apesar de $95,4 \%$ da população estar alfabetizada. Somente $7,7 \%$ da população municipal têm ensino superior (PREFEITURA DE SÃO BERNARDO DO CAMPO, 2008). O debate que acontece dentro do Conselho tem contornos técnicos, que exigem preparação prévia. Como relatado pela pesquisa de campo, $80 \%$ dos conselheiros gostariam de receber algum tipo de preparo para exercer sua função, dado que revela que a participação em espaços setoriais, como a educação, ainda demanda uma preparação que não está ao alcance de todos. Não se pode esperar que a população participe ativamente se não consegue compreender o que ocorre no Conselho. Essa tese é consoante com o proposto por Miranda (2006), quando acredita que ainda conservamos as marcas de uma sociedade fortemente verticalizada, onde existem sempre seres descolados da sociedade, escolhidos como representantes justamente pela diferença, e não pela igualdade, reforçando também a fala de Ferreira (1993).

Abers e Keck (2007) apontam uma terceira proposição, referente à imposição da agenda dos Conselhos por via governamental. Conforme relatado nas entrevistas e também por Tatagiba (2005), a agenda ainda é dominada pelas necessidades do Poder Público, e não da sociedade. Em São Bernardo do Campo, esse fato pode ser expli- 
cado pelo defendido pela presidente do Conselho, que põe a predominância do Executivo como natural ao processo de transição de poder recente no município. Contudo, esse fator pode estar ligado também à centralização do poder - assim como o poder é passado para organizações colegiadas com participação da sociedade, ele precisa ser retirado das mãos de alguém. Dessa forma, é preciso analisar a possibilidade de cooptação desses mecanismos populares pelos tradicionais donos do poder, no caso, os órgãos governamentais, que veem na cooptação uma possibilidade de continuar a regular serviços, porém por meio do véu da legitimidade da sociedade organizada. Abramovay (2001) acredita, ainda, que o Conselho deveria ser um objeto de mudança de paradigmas institucionais, e não mais um instrumento de política convencional. Se a sociedade não consegue pautar o debate, existe uma maior possibilidade de se perder frente às necessidades do governo. Nesse ponto, é preciso questionar a serviço de quem o conselho existe - como representante da população ou como assessor do governo? Em tese, as duas funções deveriam ser permeáveis a ponto de não serem concorrentes, mas harmônicas entre si. Na realidade, o Conselho deveria funcionar como alternativa ao modelo de sociedade em oposição ao Estado, mas o próximo item considerado por Abers e Keck (2007) afirma o contrário: os Poderes Executivos por trás dos conselhos têm dificuldade de abrir mão de seu próprio poder e passá-lo efetivamente aos colegiados, hipótese intimamente ligada ao quarto ponto em debate.

No objeto de estudo em questão, esta hipótese está colocada quando a função do conselho é predominantemente consultiva, pouco executora. A dificuldade de consenso entre as partes, tão evidente no estudo de caso, pode ser um indício que isso aconteça de fato. Contudo, os próprios conselheiros da sociedade civil, já acostumados com os destratos governamentais, se colocam em posição de batalha, com aparente indisponibilidade para um diálogo que conduza a soluções benéficas para as duas partes envolvidas. Voltamos ao ponto de questionar a quem o Conselho serve, e para quem está sendo utilizado o espaço disponibilizado e conquistado pela caminhada democrática brasileira. Muitas vezes, em vez de centrado em questões deliberativas e na busca de um consenso, a desarmonia impede que o processo seja completado, se tornando o centro da ação do Conselho - a oposição por oposição, que não caminha e não produz. É justificável, então, que existam categorias na cidade que sequer conseguem eleger representantes: existe pouco benefício em gastar horas de um dia útil de trabalho em discussões que não caminham, e que raramente deliberam. Como a esfera conselhista concentra pouco poder, o trade-off entre participar e não participar, ainda mais quando participar é pesaroso, é fácil de ser solucionado.

Young (2006) acredita que a consequência mais grave da crise de representação é a perda de legitimidade das instituições participativas frente à população - a sociedade deixa de acreditar que pode influenciar as políticas locais e deixa de participar, deixa de procurar informações sobre seus representantes e deixa de cobrar suas ações. Além dos pontos referentes à representação, que poderiam levar à consequência descrita por Young (2006), algumas outras questões podem ser relevantes como tentativas explicativas da falta de contato entre representantes e representados e das dificuldades do Conselho em se tornar esfera de deliberação efetiva.

Primeiramente, é preciso pensar no papel da comunicação dentro do Conselho. Sem o acesso à informação, que também pode ser representado pela dificuldade da população em frequentar as reuniões, dado o horário e os dias dos encontros, o cidadão fica impossibilitado de participar, situação que já era descrita por Dahl (1997) e Abrucio e Loureiro (2005). A comunicação também 
é responsável por fomentar o debate e permitir que mais pessoas estejam em sintonia com o que é tratado, gerando círculos de debate entre os representados. Assim, tendo a informação como condição básica de participação, e constatando que ela é falha, seja pela falta de diálogo, seja pela falta de prestação de contas, seja pela dificuldade de acesso, o cidadão fica impossibilitado, mesmo que queria, de participar e de se reconhecer como mandante da política, já que não tem vínculo com seu conselheiro.

Uma segunda proposta explicativa estaria relacionada à historicidade da instituição. O Conselho data dos anos 1970, mas a composição continuamente renovada, principalmente em sua última gestão, impede a criação de uma cultura da organização. Sem uma identidade própria, ainda sendo construída, como fica aparente na fala dos conselheiros, o processo de colocação de demandas, discussões e votações internas, ainda sem regras definidas pelo constante rearranjo de membros, é difícil de ser organizado de modo eficaz. Mesmo tendo em sua composição diversos professores, diretores e especialistas, a falta de um elemento conector, pela própria falta de identificação do Conselho, é barreira para a concretização de processos conduzidos para sua resolução. Abramovay (2001) coloca que

não se transferem, num passe de mágica, valores, comportamentos, coesão social e sobretudo a confiança entre os indivíduos que os estimulem a tomar em conjunto iniciativas inovadoras. (ABRAMOVAY, 2001: 124).

Assim, é preciso pesar, como coloca Tatagiba (2008), quanto do que esperamos das instituições participativas pode ser oferecido por elas, neste momento histórico. Levando em conta que o Brasil passou por uma democratização relativamente recente e ainda se encontra permeado de práticas patrimonialistas e clientelistas, as expec- tativas acerca de conselhos e outras instituições precisam ser pautadas por maior razoabilidade. Contudo, ao mesmo tempo que a necessidade de consolidação da instituição é colocada, também é preciso pensar na participação (e sua constante renovação, com novos atores entrando e saindo de cena) como chave do Conselho e, portanto, passível de enfrentar novos desafios a cada mudança de gestão.

Acharya, Gurza Lavalle e Houtzager (2004) acreditam, ainda, em outro elemento que pode explicar a crise de legitimidade de representação nos Conselhos: o próprio desenho institucional do órgão, hipótese confirmada pela presidente do Conselho. Como poucas pessoas (16 conselheiros) podem participar, poucos se sentem motivados a se envolver com as atividades conselhistas. Se fosse possível contar com mais professores, diretores e especialistas, de diversas categorias (por exemplo, profissionais das creches conveniadas, professores de todos os níveis educacionais etc., além de representantes de outras Secretarias, como Saúde e Obras), seria mais fácil identificar as demandas de forma completa. Essa proposta não necessariamente solucionaria os problemas do debate, mas seria uma contribuição de visões diferenciadas. Com um maior número de membros, também seria possível organizar o trabalho em comissões, com o objetivo de estudar mais profundamente os temas tratados, trazendo racionalidade às discussões.

É preciso repensar, também, até que ponto é plausível que existam mecanismos de prestação de contas e diálogo do representante com toda a sua categoria. Os conselheiros não são remunerados por seu trabalho, o que pressupõe que têm suas próprias obrigações laborais, até mesmo para serem eleitos como representantes das categorias. Assim, sobra pouco tempo para reuniões e debates que envolvam todos os que deveriam estar representados naquela instância. Uma alternativa a esse problema seria aumentar o número 
de representantes, como já proposto, com cada conselheiro sendo "responsável" por um menor número de pessoas, mas outro caminho que também pode ser tomado é a criação de uma rede de conselhos, responsáveis pelas discussões que seriam levadas aos representantes, solução que será desenvolvida a seguir, como parte das recomendações.

\section{Estratégias de encaminhamento para um Conselho responsável}

Esta seção se destina a procurar alguns caminhos que poderiam ser úteis ao Conselho em sua tarefa de melhor representar os que, mesmo sem saber, têm no Conselho um centro fértil de poder - e, portanto, capaz de empoderar.

Young (2006) crê na necessidade de uma democracia comunicativa, onde os cidadãos chamam os representantes para os processos de comunicação - prestação de contas contínua, e não somente nos momentos de autorização (YOUNG, 2006). Fica claro que a tônica da mudança é a ênfase em mecanismos de entendimento entre representantes e representados, para que a sociedade inteira se aproprie do Conselho, e não só seus membros eleitos. Mais do que uma lei que obrigue conselheiros a prestar contas, é preciso dar condições para que a prestação não só informe, mas construa um conhecimento sobre o que é trabalho no interior do Conselho e instigue os que estão fora da arena do debate a participar.

Esse debate não precisa acontecer, propriamente, no nível do Conselho Municipal de Educação. Se houver um esforço para a estruturação de uma rede capilar de conselhos, partindo dos Conselhos Escolares até o Conselho Municipal, torna-se mais simples o processo comunicativo. Se, dentro de cada célula educacional, os pais e responsáveis forem chamados ao debate e "tomarem conta" de seu microcosmo, dialogando com professores, di- retores e outros pais, eles se tornam capazes de regular o Conselho Municipal, por sua coesão interna. Dessa forma, diversos problemas podem ser solucionados ao olharmos para a estruturação de pequenos grupos. Não se pode exigir que todos os pais, responsáveis, professores e diretores estejam presentes em todas as reuniões do Conselho, mas pode-se exigir que compareçam e contribuam para o debate em suas unidades de ensino. Essas unidades de ensino, uma vez organizadas, podem levar seu debate interno, por meio de seus representantes, aos conselheiros de suas categorias. As demandas organizadas nas bases são mais passiveis de serem decodificadas pelos Conselheiros, que podem prestar uma representação mais eficiente. Da mesma maneira, conselhos escolares organizados podem pedir contas das ações de seus representantes, regulando-os. Young (2006) coloca a importância da coesão do grupo como fator-chave para uma representação eficaz. Se o conselheiro não consegue identificar as demandas de sua classe, por estar demasiadamente diluída entre todos os representados desorganizados, só lhe resta supor quais são suas vontades de acordo com sua perspectiva equânime, fato recorrente no Conselho, que pôde ser observada pelas falas dos conselheiros. Não se pode delegar a representação pela própria falta de identidade do grupo. Só pode ser devidamente representado o grupo com um mínimo de harmonia (YOUNG, 2006).

As vias institucionais podem ser eficazes para a promoção de uma melhor representação, no sentido de promover grupos mais coesos a serem representados no Conselho. Como proposto pela presidente atual do Conselho, trazer membros mais específicos para cada categoria tornaria os interesses de cada setor mais identificáveis. Os representados de cada conselheiro teriam mais facilidade para se reunir e dialogar, visto que enfrentam as mesmas necessidades. Assim, em vez de um professor para toda a rede pública fundamental, trazer um professor para cada nível de ensino, 
ou para cada região, visto que São Bernardo conta com 33 bairros e taxas de vulnerabilidade de alta até muito baixa, ${ }^{2}$ revelando as disparidades existentes dentro da própria cidade. Os IDEBs de 2009, referentes ao município, variam de 4,2 até $6,9,{ }^{3}$ o que mostra que as unidades escolares têm necessidades diferentes a serem debatidas pelo Conselho. Além disso, setores complementares ao da Educação, como Assistência Social, também poderiam trazer contribuições, no sentido de assistência técnica e informação, e por isso devem ser pensados como parceiros a estarem presentes na estrutura do Conselho, segundo sugestão da presidente do Conselho.

Além da necessidade institucional de tornar a representação mais plural e menos generalista, é preciso pensar no modo como o trabalho está dividido dentro do Conselho. Apesar de contar com um plano de trabalho para todo o ano, os itens da pauta às vezes se perdem em meio às discussões, além de serem postergados em razão das urgências. Além de tornar o Conselho mais representativo, é preciso torná-lo mais eficiente. Uma das soluções propostas pela presidente do Conselho é dividi-lo em pequenas comissões, que seriam então responsáveis por se aprofundar num determinado assunto e trazer o que foi debatido para o grupo, de forma organizada. Esse sistema pouparia um tempo valioso de discussão que acontece pela falta de conhecimento ou de informações, seja pelo puro desconhecimento, seja pelo fato de a informação ser referente a algum setor não representado no Conselho. Essas duas propostas - aumentar o número de conselheiros e dividir as tarefas - são então complementares, pois trabalham juntas à medida que trazem mais informação para os Conselheiros. O feedback das informações para os representados também depende desses movimentos: é mais fácil prestar contas (e cobrar) à medida que a classe é mais específica - aspecto de "quem" cobrar/prestar contas; e, quando existem fatos e resoluções con- cretas advindas do Conselho, é mais fácil saber "o que" cobrar e "do que" prestar contas.

Portanto, quatro frentes podem ser otimizadas para a melhoria da representação no Conselho: a comunicativa, proposta por Young (2006), objetivando amenizar as assimetrias de informação; a institucional/gerencial, no sentido de aumentar o número de conselheiros e dividir o trabalho internamente; a estruturante, para a criação de uma rede desde os Conselhos Escolares até o CMED; e a regulatória, para que os conselheiros não ajam deliberadamente, mas prestem contas de suas ações. Ressalta-se que as quatro frentes estão completamente interligadas, sendo que uma melhoria em uma causa efeito nas outras, assim como uma depende das alterações das outras para ser maximizada.

\section{CONCLUSÕES E CONSIDERAÇÕES FINAIS}

O quadro aqui relatado não difere de maneira generalista do que se observa em outros conselhos de políticas públicas, tanto em educação como em outros setores.

No tocante à representação, tópico central deste trabalho, a relação entre representantes e representados é nebulosa, por questões estruturais e de cunho social, e até pela crença de que é possível reduzir a representação a poucos membros especializados, que se dispõem a cumprir um, por vezes, pesaroso papel. Young (2006) acredita que a representação é, ao mesmo tempo, necessária e impossível: necessária como condição estrutural da democracia, e impossível por exigir do representante muito mais do que suas limitações são capazes de cumprir - a antiga dificuldade de concentrar, em alguém, todas as vontades que fariam a composição do bem público (SCHUMPETER, 1984). Assim, a solução proposta pela 
autora é mudar o conceito pelo qual enxergamos a representação. Precisaríamos superar a ideia de representação como substituição de alguém ausente, passando à definição de representação a partir da relação dos representados entre si e com o conselheiro eleito (YOUNG, 2006). Mais uma vez, a autora coloca que a representação deixa de funcionar quando os eleitores perdem o contato com seu representante. Tendo em vista a sociedade liberal em que se inserem os conselhos, esse paradigma de contato entre as partes remete à crítica de Michels (1982) sobre a individualização característica da sociedade contemporânea. A individualização dificulta a formação de laços, especialmente quando em torno de questões publicas, tornando a representação um vínculo extremamente frágil. A tentativa de fortalecê-los passa pelas sugestões apresentadas na seção anterior.

Se levarmos em conta as proposições de O'Donnell (1994), podemos considerar que o Estado, por sua proposição de contar com um conselho, reconhece que não é capaz de, sozinho, representar o interesse de todos. Ou seja, o Estado, dispondo de um Conselho, reconhece em si a quebra com a teoria da representação pura. No entanto, esse processo não fica necessariamente completo dentro de suas instituições - e de seus Conselhos. Assim, por mais que o Estado seja democrático por admitir que precise dos conselhos para melhor representar sua população, esse pensamento pode não ser verdadeiro em suas instituições. O’Donnell (1994) considera esse processo - entre a abertura para eleições democráticas e a democracia institucional de fato - como a fase delegativa da democracia: a população delega o poder para seus representantes, mas este é seu único papel no jogo político. E é papel das instituições políticas avançarem democraticamente, pela inclusão de mais atores no jogo político; e por ações que possam ser premeditadas pelos representados, ou seja, se tornem estáveis - mesmo que seus participantes mudem, que se possa esperar o mesmo comportamento deles (O'DONNELL, 1994). Assim, o Conselho não pode depender somente do comportamento de seus membros, mas deve firmar-se como instituição democrática, coerente com o desenvolvimento do Estado. O objetivo não é transformá-lo em um órgão rígido, mas confiável, que não seja lançado de um lado para outro por interesses individuais. A transformação do Conselho em instituição estável faz também que seus membros confiem mais um nos outros e trabalhem não mais em oposição, mas com objetivos comuns. A estabilidade não significa o fim dos conflitos, mas conflitos orientados para a resolução de problemas comuns. Como explica o autor,

este círculo virtuoso se completa cuando la mayoría de las instituciones democráticas logran no sólo un alcance y una fortaleza razonables, sino también una gran cantidad de interrelaciones múltiples y estables.

(O'DONNELL, 1994: 11).

Assim, democracias fortes contam com instituições democráticas. O Conselho, para ser representativo, precisa ser capaz de fornecer informações, ser contestável, compartilhar poder. Além de servir como informante para o Estado, precisa usar o seu poder para agir em nome da população, que, de forma organizada, tem como cobrar o que acontece internamente. Não é preciso que todos os envolvidos nesse processo estejam envolvidos paulatina e diariamente com o Conselho, mas que se interessem e se apropriem do poder que lhes é dado. Todos têm sua função indispensável tanto na educação básica quanto na educação para a democracia, que deve estar presente não só nas instituições, mas na vivência das pessoas em sua rotina, especialmente nos Conselhos de escola, no caso tratado. A chave para o compartilhamento do poder e para a efetiva representatividade dos Conselhos é um movimento duplo: de organização da base para monitorar os conselheiros, 
e da abertura dos conselheiros para compartilhar o poder com a sociedade. O Conselho não pode funcionar desprendido da sociedade, assim como funcionam, tradicionalmente, as representações de poder no Brasil. Já que se propõe acreditar que ele pode muito, então que a sociedade, de forma coesa, consiga provê-lo de sua devida magnitude, superando o individualismo característico das democracias liberais e caminhando para a resolução de conflitos em centros de debate.

\section{NOTAS}

${ }^{1}$ Disponível em: http://www.saobernardo.sp.gov.br/comuns/ pqt_container_r01.asp?srcpg=conselho_index. Acesso em 23 ago. 2010 .

2 Segundo o Índice Paulista de Vulnerabilidade Social - IPVS, calculado para 2000. Informação do Sumário de Dados 2009 da Prefeitura de São Bernardo do Campo.

${ }^{3}$ Segundo tabela fornecida em Reunião do CMED do dia 05 ago. 2010. O Índice de Desenvolvimento da Educação Básica (IDEB) é um instrumento do governo federal, vinculado ao INEP, que visa avaliar a qualidade da educação em cada estabelecimento de ensino, de cada cidade brasileira. A meta brasileira é atingir a nota 6,0, média dos países desenvolvidos (PORTAL DO INEP, 2011).

\section{REFERÊNCIAS}

ABERS, Rebecca; KECK, Margaret. Representando a diversidade? Estado e associações nos conselhos gestores. In: SEMINÁRIO NACIONAL DO NÚCLEO DE PESQUISA EM CIÊNCIAS SOCIAIS, 2, "Movimentos Sociais, Participação e Cidadania", 2007, Florianópolis.

ABRAMOVAY, Ricardo. Conselhos além dos limites. In: Estudos Avançados, São Paulo, 15 (43), 2001.

ABRUCIO, Fernando Luiz; LOUREIRO, Maria Rita. Finanças públicas, democracia e accountability: debate teórico e o caso brasileiro. In: ENCONTRO DA ANPOCS, 29, 2005, Caxambu.

ACHARYA, Arnab; GURZA LAVALLE, Adrián; HOUTZAGER, Peter P. Civil society representation in the participatory budget and deliberative councils of São Paulo, Brazil. IDS Bulletin, Brighton, v. 35, n. 2, 2004.

AVRITZER, Leonardo; NAVARRO, Zander (Orgs.). A inovação democrática no Brasil. São Paulo: Cortez, 2003.
AVRITZER, Leonardo. Sociedade civil e participação social no Brasil. Brasília: Projeto Brasil em Três Tempos, 2007.

BARTHOLO JR, R. S.; MOTA, C. R., FERREIRA G. S.; MEDEIROS C. M. B. Democracia, participação e direito: o papel dos conselhos nas políticas sociais brasileiras. In: CONGRESO INTERNACIONAL DEL CLAD SOBRE LA REFORMA DEL ESTADO Y DE LA ADMINISTRACIÓN PÚBLICA, 8, 2003, Panamá.

BRESSER-PEREIRA, Luiz Carlos. O modelo estrutural da gerência pública. Rio de Janeiro: Revista de Administração Pública, EBAPE/FGV, mar/abr 2008.

DAGNINO, Evelina. Sociedade civil, participação e cidadania: de que estamos falando? In Daniel Mato (Coord.), Políticas de ciudadania y sociedad civil em tiempos de globalizácion. Caracas: Faces, Universidad Central de Venezuela, 2004, p. 95-110.

DAHL, Robert. Poliarquia. São Paulo: Edusp, 1997.

GURZA LAVALlE, Adrián Gurza; HOUTZAGER, Peter P.; CASTELLO, Graziela. Democracia, pluralização da representação e sociedade civil. In: Lua Nova, São Paulo, ${ }^{\circ}$ $67,2006 a$.

GURZA LAVAlLE, Adrián Gurza; HOUTZAGER, Peter P; CASTELLO, Graziela. Representação Política e Organizações Civis: Novas instâncias de mediação e os desafios da legitimidade. In: Revista Brasileira de Ciências Sociais, São Paulo, vol. 21, número 60, fevereiro/2006b.

FERREIRA, Nilda Teves. Cidadania: uma questão para a educação. Rio de Janeiro: Nova Fronteira, 1993.

FUNG, Archon. Receitas para esferas públicas: oito desenhos institucionais e suas conseqüências. In: COELHO, Vera S. P.; NOBRE, Marcos (Orgs.). Participação e deliberação. São Paulo: Editora 34, 2004.

INSTITUTO BRASILEIRO DE GEOGRAFIA E ESTATÍSTICA. Perfil dos municípios brasileiros 2009. Rio de Janeiro: IBGE, 2010.

LAMOUNIER, Bolívar. Da independência a Lula: dois séculos de política brasileira. São Paulo: Augurium, 2005.

LEITE, Cristiane Kerches da Silva; PERES, Ursula Dias; IGLECIAS, Wagner. GT 12: Desafios e dimensões contemporâneas do desenvolvimento - Agendas governamentais de desenvolvimento: uma análise comparativa da implementação de políticas de saúde no Brasil, Argentina e Chile. In: ENCONTRO ANUAL DA ANPOCS, 33, 2009, Caxambu.

LÜCHMANN, Lígia Helena Hahn. A representação no interior das experiências de participação. In: Lua Nova, São Paulo, 70, 2007. p. 139-170.

MANIN, Bernard; PRZEWORSKI, Adam; STOKES, Susan. Eleições e representação. In: Lua Nova, São Paulo, 67, 2006 a.

MICHELS, Robert. A sociologia dos partidos políticos. Brasília: UnB, 1982. 
MIRANDA, Sandro Ari de Andrade. Breve histórico do pensamento conservador brasileiro, a "povofobia", e o nascimento da democracia participativa. In: Revista Âmbito Jurídico, Revista Eletrônica n. 25, Rio Grande, RS, ano IX, janeiro/2006.

O'DONNELL, Guillermo. Delegative democracy. In: Journal of Democracy, Baltimore, v. 5, n. 1, Jan/1994.

PÓ, Marcos Vinícius; PRADO, Otávio. Discursos, prestação de contas e responsabilização democrática nas reformas da gestão pública. In: ENCONTRO DA ANPAD, 31, 2007, Rio de Janeiro.

PORTAL DO INSTITUTO NACIONAL DE ESTUDOS E PESQUISAS EDUCACIONAIS ANISIO TEIXEIRA. Disponível em: http://portalideb.inep.gov.br/. Acesso em 17 mar. 2011.

PREFEITURA DE SÃO BERNARDO DO CAMPO. Sumário de Dados 2009 de São Bernardo do Campo (ano-base 2008). 2009. Disponível em: http://www.saobernardo.sp.gov.br/dadosl/ arquivos/sumario/SBC_DADOS_Completo.zip. Acesso em 10 ago. 2010.
ROCHA, Selma. Fundos públicos e sistemas de ensino na cidade de São Paulo. São Paulo: Instituto Pólis/PUC-SP, 2003.

SANTOS, Boaventura Souza. Democratizar a democracia. São Paulo: Civilização Brasileira, 2002.

SCHUMPETER, Joseph. Capitalismo, socialismo e democracia. Rio de Janeiro: Zahar, 1984

TATAGIBA, Luciana. Conselhos gestores de políticas públicas e democracia participativa: aprofundando o debate. In: Revista de Sociologia Política, Curitiba, 2005.

TOCQUEVILLE, Alexis (1835). A democracia na América. Belo Horizonte: Itatiaia/EDUSP, 1977.

YOUNG, Iris Marion. Representação política, identidade e minorias. In: Lua Nova, São Paulo, n. 67, $2006 a$. 